\title{
Severe Anomalies Associated With Ring Chromosome 7
}

Leslie G. Biesecker, Beth Cox, and Thomas W. Glover

Departments of Pediatrics and Communicable Diseases (L.G.B., T.W.G.), Pathology (B.C.) and Human Genetics (T.W.G.), University of Michigan Medical School, Ann Arbor, Michigan

A newborn infant with the polyasplenia sequence, intrauterine growth retardation, cutaneous nevi, and minor anomalies was found to have mosaicism for ring chromosome 7. This patient's anomalies are markedly different from those of previous patients reported with this cytogenetic anomaly.

KEY WORDS: chromosomes, asplenia, Ivemark "syndrome," growth retardation, mosaicism, abnormalities: multiple, ring chromosome, chromosome 7

\section{INTRODUCTION}

Seven previous cases of ring chromosome $7(r(7))$ have been reported in association with minor anomalies with and without mental retardation [Zackai and Breg, 1973; Nakano and Miyamoto, 1977; DeLozier et al., 1982; Barros et al., 1986; Kohyama et al., 1988; Koiffmann et al., 1990]. All of the reported patients had evidence of mosaicism with the $r(7)$ line predominating and low frequencies of double rings, monosomy 7 , duplicated rings, normal and other karyotypes. The discussion in these cases has centered on the variation in clinical manifestations in spite of apparently similar chromosome rearrangements and levels of mosaicism. The anomalies in the present patient are far more severe than those reported previously and broaden the spectrum of the ring 7 phenotype.

\section{CLINICAL REPORT}

The patient was a 3-day-old male of 37 weeks gestation born to a 26-year-old primigravid woman. The father was 28 years old. The patient's BW was $2.46 \mathrm{~kg}$ (25th centile), BL was $43 \mathrm{~cm}(<3 \mathrm{rd}$ centile), and birth

Received for publication June 18, 1990; revision received January $21,1991$.

Address reprint requests to Leslie G. Biesecker, M.D., University of Michigan Department of Pediatrics and Communicable Diseases, D1109 M.P.B. Box 0718, Ann Arbor, MI 48109.
OFC was $29.5 \mathrm{~cm}$ ( $<3 \mathrm{rd}$ centile). At birth he was noted to have a murmur and multiple congenital anomalies and was transferred to a regional center where complex congenital cyanotic heart disease was diagnosed. Prostaglandins were administered and he was transferred to this institution.

On physical examination he was noted to have large capillary hemangiomata of the forehead, occiput, back, and neck. The skin of his neck, back, and scalp was redundant. A darkly pigmented nevus was present on the left thigh $(4 \mathrm{~cm})$. His palpebral fissures were wide $(2.3 \mathrm{~cm})$ and his ears were short $(3 \mathrm{~cm})$. One earlobe had oblique cutaneous creases. A murmur and a unilateral hydrocele were present. His suck reflex was described as fair and his Moro and deep tendon reflexes were normal.

An echocardiogram documented situs inversus, d-loop, d-transposition of the great vessels, virtual pulmonary atresia, unbalanced atrioventricular septal defect, left ventricular hypoplasia, and a common atrioventricular valve with $1+$ insufficiency. The left inferior vena cava, left superior vena cava, and hepatic veins drained into the left atrium and a large patent ductus arteriosus supplied the branch pulmonary arteries and right aortic arch. Abdominal ultrasound images indicated situs inversus abdominis and a liverspleen scan confirmed inversion of the liver and spleen with a normal spleen signal. A cranial ultrasound scan was normal.

At age 4 days a modified left Blalock-Taussig shunt procedure was performed. Although adequate shunt function was achieved, the patient deteriorated. Multiple blood cultures demonstrated Klebsiella pneumoniae in spite of appropriate doses of antibiotics with demonstrated in vitro efficacy against this organism. HowellJolly bodies were seen in blood smears. He died at 28 days of respiratory and renal failure. An autopsy was performed and confirmed the presence of complete situs inversus of abdominal organs with a clefted, multilobed spleen and partial situs inversus of the thoracic organs. The portions of the heart and great vessels above the ventricles were inverted and the ventricles remained in the usual location. Both lungs were bilobed. Additional findings included bronchopneumonia, fatty changes in the liver with patchy fibrosis, diffuse leukoencephalopathy of the brain with microcephaly $(207 \mathrm{~g})$, and focal renal tubular and glomerular necrosis. 


\section{CYTOGENETIC STUDIES}

Giemsa-banded chromosomes were prepared from peripheral blood lymphocytes by the usual methods. The study resolution was 650 bands per haploid karyotype. The modal number of chromosomes was 46 . Of 40 cells counted 35 were 46,XY,r(7)(p22q36) (Fig. 1), 2 were 46,XY,partial dup $\mathbf{r}(7), 1$ was 46,XY,dup $r(7), 1$ was $46, \mathrm{XY}$, der r(7) (smaller ring), and 1 was $45, \mathrm{XY},-7$. Both parents had normal chromosomes.

\section{DISCUSSION}

This patient is the eighth child to be described with a ring 7 chromosome. In addition, several patients have been reported to have a ring chromosome of group $\mathrm{C}$ $[r(C)]$ in the prebanding era [Turner et al., 1962; Atkins et al., 1966a,b; Butler et al., 1967; Wurster et al., 1969; Gacs et al., 1970; Kistenmacher and Punnett, 1970; Therkelsen et al., 1971; de Chieri et al., 1972]. The patient reported here had more severe anomalies than the previously described $r(C)$ and $r(7)$ patients, although he shares certain findings that have previously been noted in the r(7) patients. Growth retardation, developmental delay, cutaneous lesions, skeletal anomalies, and microcephaly are common in the $\mathbf{r}(7)$ patients.

Congenital heart defects reported in the $\mathrm{r}(\mathrm{C})$ patients included an atrial septal defect (ASD), ventricular septal defect, and bicuspid pulmonary valve in one patient [Butler et al., 1967] and ASD in one [Turner et al., 1962]. No cardiac anomalies were reported in the $r(7)$ patients. The combination of complex cyanotic congenital heart disease with situs inversus and splenic dysfunction suggests presence of the polyasplenia sequence of Ivemark "syndrome" which is an etiologically heterogeneous field defect [Toriello et al., 1986]. However, growth retardation, microcephaly, and nevi are not typical of this sequence or field defect. Polysplenia has been associated with a number of chromosome anomalies [Schinzel, 1983 ] and it is reasonable to conclude that abnormal-

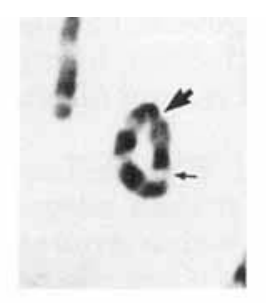

a

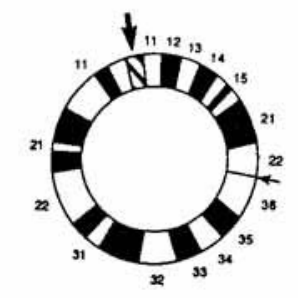

d

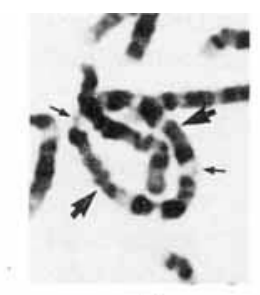

b

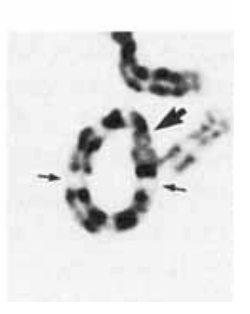

c

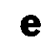

Fig. 1. Abnormal number 7 chromosomes: (a) single ring 7, (b) dup ring 7 , (c) der ring 7, (d) diagrammatic single ring 7, (e) partial dup ring 7 . ities of laterality determination are a nonspecific effect of aneuploidy or that there are a number of genes scattered throughout the genome that participate in the determination of laterality.

The average ages of the mothers and fathers of $r(7)$ patients were 30 and 34 years, respectively. Both of these averages are significantly increased compared to the average age of childbearing in the U.S. $(P<.05$, one tailed $t$ test), as is known to be the case for structural chromosomal abnormalities in general [Therman, 1986]. Chromosomes of 8 sibs of the previously reported r(7) patients were normal. Parental chromosomes were normal in all cases except the report by Nakano et al. [1977] which states that the mother of the propositus had an abnormal karyotype including a D-group ring in $1 \%$ of cells, a D-C translocation in $1 \%$, an inversion $\mathrm{C}$ in $1 \%$, trisomy $\mathrm{C}$ in $3 \%$, and trisomy $\mathrm{C}$, inv( 3 , and acentric in $1 \%$. Of note is the fact that this woman was $4 \mathrm{~km}$ from the epicenter of the Nagasaki nuclear explosion and is estimated to have received $1 \mathrm{rad}$ of exposure. The father of the patient reported here is a service technician in a nuclear power plant. Records obtained from the power plant indicate that the father's exposure during his 3 year work history was 1.09 rads. Much speculation has centered around the issues of genetic damage, specifically chromosomal, in persons exposed to ionizing radiation. Similar to the conclusion of Nakano et al. [1977], we think it is extremely unlikely that such an exposure level would be causally related to this chromosome anomaly.

The cytogenetics of $r(7)$ patients are similar. Of the 6 cases in which such data were presented, all have mosaicism with the $46, r(7)$ line in 84 to $98 \%$ of analyzed cells (Table I). One report [Kohyama et al., 1988] noted that the $\mathbf{r}(7)$ cell line was present in $100 \%$ of cells at $48 \mathrm{hr}$ of culture but dropped to $92 \%$ at $72 \mathrm{hr}$, suggesting instability of the ring. The mosaicism frequencies have been evaluated in blood ( 5 of 6 previous cases), bone marrow [Nakano and Miyamoto, 1977], and normal and abnormal skin samples [DeLozier-Blanchet and Guenin, 1984; Zackai and Breg, 1973]. All are consistent with the exception of the case reported by DeLozier-Blanchet and Guenin [1984] in which the lymphocytes demonstrated $r(7)$ in $98 \%$ whereas normal and abnormal skin cells demonstrated $r(7)$ in 1.5-14\%. Other karyotypes in affected patients included dicentric rings, double sized rings, monosomy 7,2 single size rings, monosomy 7 with double minutes or fragments, and euploid. These lines were expressed at levels of $2-6 \%$. The subject of the current report demonstrated the $r(7)$ in $35 / 40$ cells (88\%). In 5/40 cells there were various karyotypes with abnormalities of chromosome 7 similar to those described above. The breakpoints of the ring reported by Kohyama et al. [1988] are identical to those seen in our patient (p22q36). The rings studied by Zackai and Breg [1973] reportedly had "all bands present" and the ring studied by DeLozier et al. [1982] had "minimal loss of chromosomal material." The breakpoints reported by Nakano et al. [1977], Barros et al. [1986], and Koiffmann et al. [1990] were not specified but the ring was said to have a similar banding pattern to a normal chromosome 7 . The cytogenetic findings suggest that 
TABLE I. Karyotype Frequency in Ring 7 Reports, by Author $\dagger$

\begin{tabular}{|c|c|c|c|c|c|c|}
\hline Karyotype & $\begin{array}{c}\text { Zackai et al. } \\
(1973)\end{array}$ & $\begin{array}{c}\text { Zackai et al. } \\
(1973)\end{array}$ & $\begin{array}{c}\text { Nakano et al. } \\
(1977)\end{array}$ & $\begin{array}{c}\text { DeLozier et al. } \\
(1982)\end{array}$ & $\begin{array}{c}\text { Kohyama et al. } \\
(1988)\end{array}$ & This Report \\
\hline \multirow{7}{*}{$\begin{array}{l}46, \mathbf{r}(7) \\
45,-7 \\
46 \\
46, \operatorname{dup} \mathrm{r}(7) \\
47, \mathrm{r}(7), \mathrm{r}(7) \\
47, \text { dup } \mathrm{r}(7) \text {,dup } \mathrm{r}(7) \\
46, \text { der } \mathrm{r}(7) \\
45,-\mathrm{N}\end{array}$} & $57(.90)$ & $52(.84)$ & $140(.86)$ & $96(.96)$ & $46(.92)$ & $35(.88)$ \\
\hline & $2(.03)$ & $4(.06)$ & $6(.04)$ & & $3(.06)$ & $1(.02)$ \\
\hline & $1(.02)$ & $2(.03)$ & $1(*)$ & & & \\
\hline & $2(.03)$ & $1(.02)$ & $8(.05)$ & & $1(.02)$ & $3(.08)$ \\
\hline & $1(.02)$ & $3(.05)$ & $1\left(^{*}\right)$ & $3(.03)$ & & \\
\hline & & & & $1(.01)$ & & $1(.02)$ \\
\hline & & & $5(0.3)$ & & & \\
\hline
\end{tabular}

$\dagger-\mathrm{N}$, monosomy (chromosome unspecified); numbers in table are cells counted (fraction of total); *, less than $1 \%$.

the ring chromosome is unstable and the cytogenetic constitution of tissues other than blood or skin is unpredictable.

It is apparent that the phenotype of $r(7)$ patients does not correlate with either the breakpoints of the ring at current levels of banding resolution or with the mosaicism frequencies as both are similar in all patients for whom such data were provided, in spite of the significant variation in clinical features. Kosztolanyi [1987] has advanced the hypothesis that ring chromosome patients share a basic phenotype of growth and mental retardation with minor anomalies due to the ring structure in the absence of a deletion and secondary mitotic instability regardless of the chromosome involved. More severe anomalies are due to deletion of subtelomeric chromosome segments. On the basis of clinical findings, the patient presented here would belong to the latter group of this hypothesis due to his severe anomalies while the previous seven cases would belong to the former. However, the apparently similar breakpoints in ring formation and similar mosaicism among patients with markedly dissimilar phenotypes do not suggest a simple phenotype/karyotype correlation. We agree with the previous authors who speculate that the phenotypic variation could be attributed to aneusomy in the subtelomeric areas below the resolution of current studies or to variations in levels of mosaicism in tissues not analyzed secondary to mitotic instability of the ring chromosomes.

\section{ACKNOWLEDGMENTS}

The authors wish to thank Dr. Mason Barr, Jr. for his critical review of the manuscript and Dr. C. Koiffmann for providing the Barros et al. abstract.

\section{REFERENCES}

Atkins L, Pant SS, Hazard GW, Ouellette EM (1966a): Two cases with a C-group ring autosome. Ann Hum Genet 30:1-6.

Atkins L, Sceery RT, Keenan ME (1966b): An unstable ring chromosome in a female infant with hypotonia, seizures, and retarded development. J Med Genet 3:134-138.
Barros LP, Perez ABA, Brunoni D, Andrade JAD (1986): Cromosomo 7 em anel-relato de um caso. Cienc Cult 38(suppl):849 (abstract).

Butler LJ, France NE, Jacoby NM (1967): An infant with multiple congenital anomalies and a ring chromosome in group $\mathrm{C}(\mathrm{X}-6-12)$. J Med Genet 4:295-298.

de Chieri PR, Albores JM, Cosin A, Cosin JM (1972): A human ring C chromosome associated with multiple congenital anomalies. $J$ Med Genet 9:239-242.

DeLozier CD, Theintz G, Sizonenko P, Engel E (1982): A fourth case of ring chromosome 7. Clin Genet 22:90-98.

DeLozier-Blanchet CD, Guenin R (1984): Cytogenetics of ring chromosome 7. Clin Genet 25:84-85 (letter).

Gacs G, Schuler D, Sellyei M (1970): Familial occurrence of congenital malformations and ring chromosome $(46, \mathrm{XX}, \mathrm{Cr})$. J Med Genet $7: 177-179$.

Kistenmacher ML, Punnett HH (1970): Comparative behavior of ring chromosomes. Am J Hum Genet 22:304-318.

Kohyama J, Watanabe S, Nakajima M, Suzumura H, Ishikawa T, Ishikawa K, Saito F, Fukuda C (1988): Ring chromosome 7: Report of a case. Acta Paediatr Jpn 30(4):517-519.

Koiffmann CP, Diament A, de Souza DH, Wajntal A (1990): Ring chromosome 7 in a man with multiple congenital anomalies and mental retardation. J Med Genet 27:462-464.

Kosztolyani G (1987): Does "ring syndrome" exist? An analysis of 207 case reports on patients with a ring autosome. Hum Genet 75:174179.

Nakano S, Miyamoto N (1977): A ring C7 chromosome in a mentally and physically retarded male with various somatic abnormalities. Jinrui Idengaku Zasshi (Jpn J Human Gen) 22:33-41.

Schinzel A (1983): "Catalogue of Unbalanced Chromosome Aberrations in Man." Berlin: de Gruyter.

Therkelsen AJ, Moller B, Henningsen K (1971): A group-C ring chromosome in a mentally deficient male. $J$ Med Genet 8:227-230.

Therman E (1986): "Human Chromosomes," 2nd ed. New York: Springer-Verlag.

Toriello HV, Kokx N, Higgins JV, Hofman R, Waterman DF (1986): Sibs with the polyasplenia developmental field defect. Am J Med Genet 2(suppl):31-36.

Turner B, Jennings AN, den Dulk GM, Stapleton T (1962): A selfperpetuating ring chromosome. Med J Aust 49:56-58.

Wurster D, Pomeroy J, Benirschke K, Hoefnagel D (1969): Mental deficiency and malformations in a boy with a group $\mathrm{C}$ ring chromosome: 46,XY, cr. J Mental Def Res 13:184-190.

Zackai EH, Breg WR (1973): Ring chromosome 7 with variable phenotypic expression. Cytogenet Cell Genet 12:40-48. 